Editors' Note: Motor involvement is not considered a typical feature of Fabry disease (FD). However, recent studies reported slower gait, reduced hand speed, and poorer fine manual dexterity, independently of cerebrovascular symptoms, in patients with FD. To further study alterations in motor circuits of patients with FD, Cocozza et al. used resting-state (RS)-fMRI. RS-fMRI is a powerful, noninvasive method used to evaluate interactions occurring between different brain structures. The authors found a reduction of functional connectivity (FC) compared to healthy controls, which is in line with the recently suggested subclinical involvement of motor circuits in this disease. Commenting on the study, Sechi et al. ask about the usefulness of RS-fMRI in detecting subtle and potentially reversible "biochemical brain lesions" in patients with FD early in the disease course. They share an earlier investigation in which they analyzed the effect of 1 year of enzyme replacement therapy (ERT) on cortical excitability in 5 patients with FD without brain MRI lesions, and an increase of excitatory neurotransmission in motor cortex circuits, documented by transcranial magnetic stimulation (TMS). They found reduction in motor cortex hyperexcitability in all patients after ERT, indicating the possible utility of TMS, and other techniques such as RS-fMRI, in monitoring the disease course and the response to therapy. Cocozza et al. agree with the need to study the relationship between functional changes and disease course. However, in their study, RS-fMRI alterations were present in successfully treated patients. They suggest that longitudinal studies with suitable sample sizes assessing both FC and motor cortex excitability are needed. According to Cocozza et al., only this approach will demonstrate if FC changes are related to a residual, nonreversible hyperexcitability, or if different neural circuit alterations are probed by the 2 techniques. Parinaud syndrome (PS) consists of vertical gaze palsy, pupil lightnear dissociation, convergence-retraction saccades, and lid retraction. $\mathrm{PS}$ is caused by a pretectal lesion involving the posterior commissure. Commenting on "Teaching Neurolmages: Acute Parinaud syndrome," Vanikieti et al. argue that eyelid retraction, rather than ptosis, is typical of dorsal midbrain lesions. They suggest that the lesion in the reported patient was more extensive than is typical in PS. Drs. Swinkin and Bui, authors of the Neurolmage, explain that they used the title "Acute Parinaud syndrome" to highlight the presence of pupillary light-near dissociation, impairment of upgaze, and convergence-retraction saccades. They agree that their patient had Parinaud plus.

-Chafic Karam, MD, and Steven Galetta, MD

LETTER RE: ALTERATIONS OF FUNCTIONAL CONNECTIVITY OF THE MOTOR CORTEX IN FABRY DISEASE: AN RS-fMRI STUDY

GianPietro Sechi, Rita Demurtas, William Boadu,

Enzo Ortu, Sassari, Italy: Cocozza et al. ${ }^{1}$ confirmed, by use of resting-state (RS)-fMRI, previous clinical and electrophysiologic studies showing involvement of cerebral motor circuits in Fabry disease (FD), independently of cerebrovascular signs/symptoms and brain MRI lesions. ${ }^{1-3}$ In particular, they showed alterations of functional connectivity in a polysynaptic motor circuit involving motor cortices, basal ganglia, and right cerebellar hemisphere. ${ }^{1}$ In metabolic/lysosomal storage diseases, a subclinical CNS impairment is common and may be related, regardless of brain MRI findings, either to a structural irreversible or to a biochemical reversible brain lesion. ${ }^{4,5} \mathrm{~A}$ crucial unsettled question in the article is the usefulness of RS-AMRI in detecting subtle and potentially reversible biochemical brain lesions in patients with FD at a rather early appearance. We investigated this question in a previous study by analyzing the effect of 1 year of enzyme replacement therapy (ERT) on cortical excitability in 5 patients with FD without brain MRI lesions, and an increase of excitatory neurotransmission in motor cortex circuits, documented by transcranial magnetic stimulation (TMS). ${ }^{3}$ We observed a reduction in motor cortex hyperexcitability in all patients after ERT, indicating the possible utility of TMS, and likely of other techniques such as RS-fMRI, in monitoring the disease course and the response to therapy.

1. Cocozza S, Pisani A, Olivo G, et al. Alterations of functional connectivity of the motor cortex in Fabry disease: an RSfMRI study. Neurology 2017;88:1822-1829.

2. Lohle M, Hughes D, Milligan A, et al. Clinical prodromes of neurodegeneration in Anderson-Fabry disease. Neurology 2015;84:1454-1464.

3. Ortu E, Fancellu L, Sau G, et al. Primary motor cortex hyperexcitability in Fabry's disease. Clin Neurophysiol 2013;124:1381-1389.

4. Perretti A, Parenti C, Balbi P, et al. Study of multimodal evoked potentials in patients with type 1 Gaucher's disease. J Child Neurol 2005;20:124-128.

5. Sechi G, Serra A. Wernicke's encephalopathy: new clinical settings and recent advances in diagnosis and management. Lancet Neurol 2007;6:442-455.

(C) 2017 American Academy of Neurology

\section{AUTHOR RESPONSE: ALTERATIONS OF}

FUNCTIONAL CONNECTIVITY OF THE MOTOR CORTEX IN FABRY DISEASE: AN RS-fMRI STUDY

Sirio Cocozza, Antonio Pisani, Arturo Brunetti, Mario Quarantelli, Enrico Tedeschi, Naples, Italy: We thank Sechi et al. for the comments on our article. ${ }^{1}$ We agree that investigating the relationship between 
functional changes and disease course is a core issue for defining the role of functional imaging in both pathophysiology and clinical studies in Fabry disease (FD). The findings of Ortu et al. ${ }^{2}$ help define the role of the functional connectivity (FC) alterations in patients. Indeed, in their study, ${ }^{2}$ motor cortex hyperexcitability partly subsided when enzyme replacement therapy was started (although the small number of patients and the incomplete reversal of transcranial magnetic stimulation findings, possibly related to insufficient follow-up, does not allow for firm conclusions due to its complete reversibility). On the contrary, we found that resting-state-fMRI alterations were present in successfully treated patients, mitigating against the hypothesis that these changes may reflect reversible FD features. ${ }^{1}$ While our view is that "a direct relationship between motor cortex hyperexcitability... and present FC changes remains speculative," longitudinal studies with suitable sample sizes assessing both FC and motor cortex excitability are needed. Only this approach will demonstrate if FC changes are related to a residual, nonreversible hyperexcitability, or if different neural circuit alterations are probed by the 2 techniques.

1. Cocozza S, Pisani A, Olivo G, et al. Alterations of functional connectivity of the motor cortex in Fabry disease: an RSfMRI study. Neurology 2017;88:1822-1829.

2. Ortu E, Fancellu L, Sau G, et al. Primary motor cortex hyperexcitability in Fabry's disease. Clin Neurophysiol 2013;124:1381-1389.

CC 2017 American Academy of Neurology

\section{LETTER RE: TEACHING NEUROIMAGES: ACUTE PARINAUD SYNDROME}

Kavin Vanikieti, Bangkok, Thailand; Marc Bouffard, Aubrey Gilbert, Joseph Rizzo, Boston: Drs. Swinkin and Bui $^{1}$ presented a patient with bilateral ptosis, light-near dissociation, impaired vertical eye movements, paresis of superior greater than inferior rectus, and upgaze-induced convergence nystagmus (saccades) from infarction of the bilateral oculomotor nuclei and mesial thalami. They concluded that these findings were consistent with Parinaud syndrome.

Neuro-ophthalmic convention considers Parinaud syndrome to correspond to dorsal midbrain syndrome. ${ }^{2}$ Eyelid retraction, rather than ptosis, is typical of dorsal midbrain lesions, as evidenced by Dr. Keane's ${ }^{3}$ review of 206 patients with Parinaud syndrome, none of whom had ptosis.

We agree the patient had injury to the oculomotor nuclei, particularly the central caudal nucleus, which, when injured in isolation, yields complete bilateral ptosis. ${ }^{4}$ Lesions in this area can also involve other subnuclei of the oculomotor nuclear complex or their emerging nerve fibers, producing ophthalmoplegia.
We agree with Drs. Swinkin and Bui that their patient experienced this type of injury, but this does not equate to classically recognized Parinaud syndrome.

Infarction in the distribution of the artery of Percheron can involve the pretectum. Indeed, this case demonstrated pupillary light-near dissociation and convergence-retraction nystagmus, implicating the pretectum. ${ }^{1}$ Collectively, these findings indicate that the lesion was more extensive than is typical in Parinaud syndrome, involving oculomotor subnuclei and pretectum.

1. Swinkin E, Bui E. Teaching NeuroImages: acute Parinaud syndrome. Neurology 2017;88:e164-e165.

2. Parinaud H. Paralysie des mouvements associes des yeux. Arch Neurol 1883;5:145-172.

3. Keane JR. The pretectal syndrome: 206 patients. Neurology 1990;40:684-690.

4. Martin TJ, Corbett JJ, Babikian PV, Crawford SC, Currier RD. Bilateral ptosis due to mesencephalic lesions with relative preservation of ocular motility. J Neuro-ophthalmol 1996; $16: 258-263$

(C) 2017 American Academy of Neurology

\section{AUTHOR RESPONSE: TEACHING NEUROIMAGES: ACUTE PARINAUD SYNDROME}

Emily Swinkin, Esther Bui, Toronto, Canada: We thank Vanikieti et al. for their comments on our NeuroImage. ${ }^{1}$

Despite the eponym, Parinaud's ${ }^{2}$ original 1883 article only described vertical gaze palsy and convergence paresis. ${ }^{3}$ It was Collier, ${ }^{4}$ in 1927 , who recognized the localizing value of vertical gaze paresis, poorly reactive pupils to light, and lid retraction to the posterior commissure.

Although Parinaud syndrome has come to signify the dorsal midbrain syndrome, this localization may be too broad for the classic collection of vertical/upgaze paresis, convergence-retraction nystagmus (saccades), light-near dissociation, and eyelid retraction. In Dr. Keane' $s^{5}$ case series, no patients had ptosis; however, he noted that the previously mentioned findings were all pretectal signs. Dr. Keane 5 suggested that "dorsal midbrain syndrome" is imprecise and may implicate a larger area with a broader range of associated signs.

Although originally called "Acute bilateral ptosis," in its development, the article title evolved to "Acute Parinaud syndrome" to highlight the unique presence of light-near dissociation, impairment of upgaze, and convergence-retraction nystagmus in this Percheron infarct. Indeed, the infarct is not a pretectal lesion as in typical Parinaud presentations; rather, it involves the oculomotor subnuclei, including the central caudal nuclei, resulting in bilateral ptosis, and affects the medial thalami. Accordingly, we agree this is Parinaud plus.

1. Swinkin E, Bui E. Teaching NeuroImages: Acute Parinaud syndrome. Neurology 2017;88:e164-e165. 
2. Parinaud H. [Paralysis of associated movements of the eyes.] Arch Neurol 1883;5:145-172.

3. Wilkins RH, Brody IA. Neurological classics: XLI: Parinaud's syndrome. Arch Neurol 1972;26:91-93.

4. Collier J. Nuclear ophthalmoplegia, with especial reference to retraction of the lids and ptosis and to lesions of the posterior commissure. Brain 1927;50: 488-498.

5. Keane JR. The pretectal syndrome: 206 patients. Neurology 1990;40:684-690.

(C) 2017 American Academy of Neurology

\section{CORRECTION}

\section{Genetics, white matter, and cognition: The effects of methylation on FMR1}

In the editorial "Genetics, white matter, and cognition: The effects of methylation on FMRI" by P.A. Nyquist and R. Hagerman, ${ }^{1}$ there are several errors in the version published online on May 5, 2017. The third sentence in the second paragraph should read "...there was increased methylation of the FMR1 exon 1/intron 1 boundary and increased transcription of this region" rather than "decreased transcription" as originally published. In addition, the first sentence of the fourth paragraph should list "FMR1 mRNA analysis normalized to EIAFA2 and SDHA" rather than "mRNA sequencing" as one of the scientific tools used in this study; the second sentence in this paragraph should read "This is done through the analysis of the mRNA expression and methylation of nucleated blood cells" rather than "...analysis of the mRNA sequencing and methylation of nucleated blood cells" as originally published. The final version, published in the May 30 , 2017, issue, is correct. The authors regret the errors.

\section{REFERENCE}

1. Nyquist PA, Hagerman R. Genetics, white matter, and cognition: the effects of methylation on FMR1. Neurology 2017;88:2070-2071. 


\section{Neurology}

\section{Genetics, white matter, and cognition: The effects of methylation on FMRI Neurology 2017;89;1844 \\ DOI 10.1212/WNL.0000000000004445}

\section{This information is current as of October 23, 2017}

Updated Information \& Services

References

Permissions \& Licensing

Reprints including high resolution figures, can be found at: http://n.neurology.org/content/89/17/1844.full

This article cites 1 articles, 1 of which you can access for free at: http://n.neurology.org/content/89/17/1844.full\#ref-list-1

Information about reproducing this article in parts (figures,tables) or in its entirety can be found online at:

http://www.neurology.org/about/about_the_journal\#permissions

Information about ordering reprints can be found online:

http://n.neurology.org/subscribers/advertise

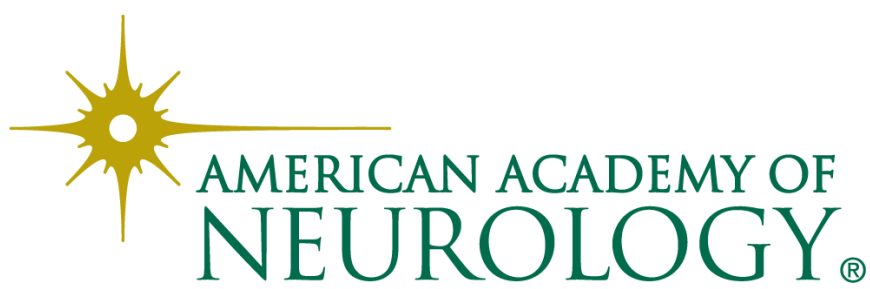

